\title{
Design for Manufacturing of an Aluminum Superplastic AA5083 Alloy Plate-Fin Heat Exchanger
}

\author{
Nuha Juneidi ${ }^{1}$, Rania Asha ${ }^{1}$, Firas Jarrar $^{2}$ \& Fahrettin Ozturk ${ }^{2}$ \\ ${ }^{1}$ Department of Mechanical Engineering, University of Jordan, Amman, Jordan \\ 2 Department of Mechanical Engineering, The Petroleum Institute, Abu Dhabi, UAE \\ Correspondence: Firas Jarrar, The Petroleum Institute, Abu Dhabi, UAE. Tel: 71-2-607-5018. E-mail: fjarrar@pi.ac.ae
}

Received: January 5, 2016 Accepted: March 4, 2016 Online Published: March 10, 2016

doi:10.5539/jmsr.v5n2p121 URL: http://dx.doi.org/10.5539/jmsr.v5n2p121

\begin{abstract}
Compact, lightweight, strong, and corrosion-resistant heat exchangers are required for many applications. In heat exchangers, plate-fin exchangers design with corrugated fins of triangular cross-sections provide high heat transfer surface area to volume ratio. This study focuses on the design for manufacturing of an aluminum AA5083 alloy plate-fin heat exchanger. The superplastic forming method is considered for the fabrication of the heat exchanger. A two-dimensional plane strain finite element model is used to study the effect of the triangular fins' aspect ratio on the thickness distribution and the required gas forming pressure cycles. The simulation results show that the thinning in deep channels can be improved by increasing the coefficient of friction but only up to a certain limit. In addition, increasing the coefficient of friction reduces the required applied pressure on the sheet and increases the forming time. The present effort represents a necessary step toward the design of sophisticated corrugated triangular fin surfaces considering both performance and manufacturability.
\end{abstract}

Keywords: AA5083, finite element simulation, plate-fin heat exchanger, superplastic forming

\section{Introduction}

The plate-fin heat exchanger (PFHE) has been widely used in aerospace and military applications. This exchanger consists of a block of layers of corrugated fins separated by parallel plates (also called parting sheets) and enclosed at the edges by side bars (Qi, Gilles, Xigang, Pierre, \& Lingai, 2011). In some cases, the parting sheets are replaced by flat tubes through which the fluid would flow (Shah \& Sekulic, 2003). The extended surfaces of the fins increase the heat transfer surface while keeping size to a minimum. Therefore, PFHEs offer a compact and lightweight solution for applications where space is a critical factor such as in offshore oil and gas facilities (Adderley \& Hallgren, 1994). Surface area to volume ratio in PFHEs may reach up to $5900 \mathrm{~m}^{2} / \mathrm{m}^{3}$ (Shah \& Sekulic, 2003). Of course, this ratio depends on the geometry of the fins. The most common fins have triangular or rectangular cross sections with typical densities ranging from 120 to 700 fins $/ \mathrm{m}$ and heights from 2 to $25 \mathrm{~mm}$ (Shah \& Sekulic, 2003). The main drawback of PFHEs is that they are mostly suitable for operating pressures of less than 0.7 MPa. However, recently the Superplastic Forming (SPF) and diffusion Bonding (DB) technologies have allowed for the fabrication of a titanium plate-fin exchanger that can handle more than $35 \mathrm{MPa}$ (Shah \& Sekulic, 2003).

Fabrication of PFHEs consists of fins forming and their joining to the parting sheets. The forming of lightweight corrugated fins with complex geometries is one of the challenges facing the PFHEs industry. A solution resides in the superplastic forming process. This process is already being used to form lightweight complex parts in one manufacturing step mainly in the automotive and aerospace industries. This is due to the significant ductility achieved in this process which is performed at high temperatures and low strain rates. In this process a pressurized gas is applied on a metal sheet stretching it into the cavity of a preheated die. The joining step is also quite important since it affects the strength and the corrosion resistance of the PFHE considerably (Adderley \& Hallgren, 1994). A novel solid-state welding technology called diffusion bonding joins materials by sticking them closely under high pressure and temperature conditions. In the process, atoms are diffused at the joining interface to complete the joint. The SPF/DB is a combined forming and joining technology that has been developed by the aerospace industry for the manufacturing of complex hollow structures (Adderley \& Hallgren, 1994). In 1994, Rolls-Royce and Associated Limited with Alfa Laval Thermal AB (Adderley \& Hallgren, 1994) were able to adapt 
the SPF/DB technology to manufacture a type of PFHE that can operate at pressures and temperatures far beyond the range allowed by conventional manufacturing techniques.

Aluminum PFHEs have been used in the aerospace and gas liquefaction applications since the 1940s and 1950s, respectively (Shah \& Sekulic, 2003). Aluminum alloys are best choice for PFHEs in terms of heat transfer rate and weight. Proper manufacturing process is important to produce a proper heat exchanger. In this present study, we consider having the SPF process as the manufacturing method for producing triangular fins made of the aluminum alloy AA5083. However, there are two main drawbacks of the SPF process. The first is the non-uniformity of the thickness distribution of the formed part. The second is the slow nature of the forming process, where forming times of at least 15 minutes are expected. The main parameters that affect both the thickness distribution and forming time are the applied gas pressure cycle, sheet-die interaction, and part geometry. Parametric studies have been carried out to identify feasible part geometries for optimum SPF. One of the first studies was that conducted by (Chandra \& Chandy, 1991). They developed a numerical tool to study the effects of a number of die geometrical features in the SPF of a long rectangular pan. Lee and Hana (2005) developed an analytical and statistical software that takes in simulation and experimental results and produces predictive formulas for the required forming time and minimum thickness of a rectangular channel. Jarrar and Nazzal (2013) used the finite element software ABAQUS $^{\mathrm{TM}}$ to simulate superplastic forming of a deep rectangular pan and investigated the effect of the wall inclination angle on the forming time and thickness distribution. In a more recent study (Jarrar, Liewald, Schmid, \& Fortanier, 2014) conducted an experimental and numerical study to investigate the optimum geometrical features of triangular channels at the base of cylindrical cups. The parts were formed using AA5083 sheets at a temperature of $500^{\circ} \mathrm{C}$.

The accurate and computationally effective simulation of the SPF is an essential step towards making it a competitive process. In this study, the finite element software ABAQUS ${ }^{\mathrm{TM}}$ is used to simulate the SPF of AA5083 plain fins with triangular cross-sections. A two dimensional (2D) plane strain model is used to predict the thickness distribution and the required forming time of straight triangular fins to be used in a PFHE. The effect of the aspect ratio of the fins on the thickness distribution is investigated.

\section{Pressure Drop Analysis}

The fin dimensions that will be used in FEM simulations are based on a pressure drop analysis procedure which is outlined in (Shah \& Sekulic, 2003) and (Kays \& London, 1964). The proposed PFHE was designed to cool a hot-air gas stream entering at $700 \mathrm{~K}$, with a cold-air stream entering at $500 \mathrm{~K}$ and leaving at $620 \mathrm{~K}$. A mass flow rate of $0.4 \mathrm{~kg} / \mathrm{sec}$ was assumed for both fluids. The inlet pressures for the cold and hot fluids were assumed to be $500 \mathrm{kPa}$ and $100 \mathrm{kPa}$, respectively. The imposed maximum allowable pressure drop used in the calculations was $3.8 \mathrm{kPa}$.

\section{Material Constitutive Model}

Under isothermal conditions, a general constitutive material model for superplastic materials can be described by:

$$
\bar{\sigma}=\mathrm{K} \bar{\varepsilon}^{\mathrm{n}} \dot{\bar{\varepsilon}}^{\mathrm{m}}
$$

where $(\bar{\sigma})$ is the effective flow stress, $(K)$ is a material constant, $(\dot{\bar{\varepsilon}})$ is the effective strain rate and $(m)$ is the strain rate sensitivity exponent. At high temperatures, the $m$ value is the major player for large deformations. The values for the material constants $K, m$, and $n$, considered in this study, are 159.5, 0.39 and 0.088 , respectively. These values are retrieved from (Luckey Jr., Friedman, \& Weinmann, 2009) and represent the superplastic response of AA5083 at $475^{\circ} \mathrm{C}$.

\section{Finite Element Model}

The finite element software ABAQUS ${ }^{\mathrm{TM}}$ was used to simulate the SPF of fins with plain triangular cross-sections. The model was considerably simplified into a $2 \mathrm{D}$ model by assuming plane strain conditions. This assumption is quite reasonable for this type of simulation. Furthermore, due to the planar symmetry of this model, only one half of the cross section was considered. Figure 1 shows the dimensions of the model considered. The horizontal dimension of die was $99.1 \mathrm{~mm}$. The die entry and bottom radii were both $0.2 \mathrm{~mm}$. The width and height of the triangular groove were 1.98 and $2.59 \mathrm{~mm}$, respectively. The flange distance was $5 \mathrm{~mm}$.

The die was modeled as an analytical rigid surface, whereas the $0.5 \mathrm{~mm}$ thick AA5083 sheet was modeled using 8 layers of 900 solid plane strain elements. Pure stretching conditions were satisfied by constraining the sheet nodes at the left and right edges. Friction between the die and sheet was assumed to be isotropic coulomb friction. The gas pressure profile was computed using an algorithm internal to ABAQUS ${ }^{\mathrm{TM}}$ that roughly maintains a maximum constant strain rate of $0.0011 / \mathrm{sec}$ in the deforming sheet. A discussion of this algorithm and comparison to 
alternative ones can be found in (Jarrar, Abu-Farha, Hector Jr., \& Khraisheh, 2009), (Jarrar, Hector Jr., Khraisheh, \& Deshpande, 2012), and (Jarrar, Hector Jr., Khraisheh, \& Bower, 2010).

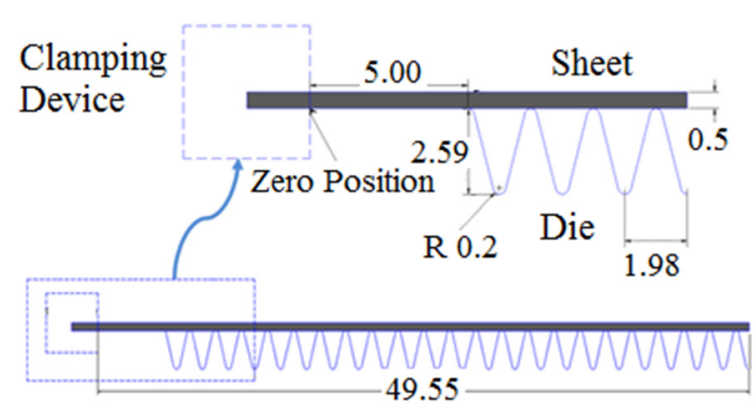

Figure 1. Die geometry representing a long multi-channel structure with triangular cross-sections. Dimensions are in $\mathrm{mm}$

\section{Results and Discussion}

\subsection{Superplastic Formability of Fins with Triangular Cross Sections Based on the Pressure Drop Analysis}

It was found by a number of researchers (Jarrar, Hector Jr., Khraisheh, \& Bower, 2010), (Ghosh \& Hamilton, 1980), (Harrison, Luckey, Friedman, \& Xia, 2004), and (Albakri, Jarrar, \& Khraisheh, 2011) that the friction conditions at the die-sheet interface strongly affect the metal flow and thus the thickness distribution during the forming process. Therefore, the SPF process of an AA5083 sheet into fins with triangular cross sections based on the dimensions from the pressure drop analysis was simulated under different friction conditions.

For a homogeneous friction distribution, the effect of friction coefficient acting at the die-sheet interface on the thickness distribution of the formed sheets is depicted in Figure 2. Points A, B, and C are points on the surface which were chosen arbitrary to discuss the thickness distribution along the surface. With low values of friction, localized thinning occurs in the vicinity of the die entry (for example points A and B). Due to the low resistance to material flow, feed from this region will continue towards the free bulging areas. This will cause substantial plastic strains at the end of the forming process. When applying higher friction coefficients, there will be more resistance to material flow from die entry region. This will increase the final thickness of this region. As a result, however, with such high friction, more thinning will occur at the die bottom corner (for example see point $\mathrm{C}$ ), as it is the last part of the sheet to get in contact with the die. This behavior noticed here is consistent with that described by Jarrar et al. (2010) and Albakri et al. (2011).

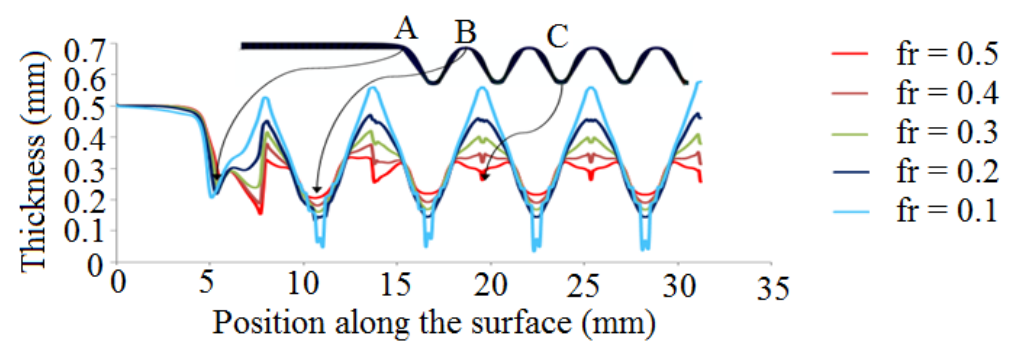

Figure 2. Predicted thickness profile of the formed sheet with different friction coefficients

Thickness uniformity throughout the formed part can be quantified using the thinning factor, which is defined as the ratio of the minimum thickness to the average thickness of the formed sheet.

$$
\text { T.F. }=\frac{t_{\min }}{t_{\mathrm{avg}}}
$$


The value of the coefficient of friction resulting in the optimal homogeneous thickness distribution for the considered geometry, where the maximum thinning factor can be obtained, was found to be $\mathrm{fr}=0.4$ as shown in Figure 3.

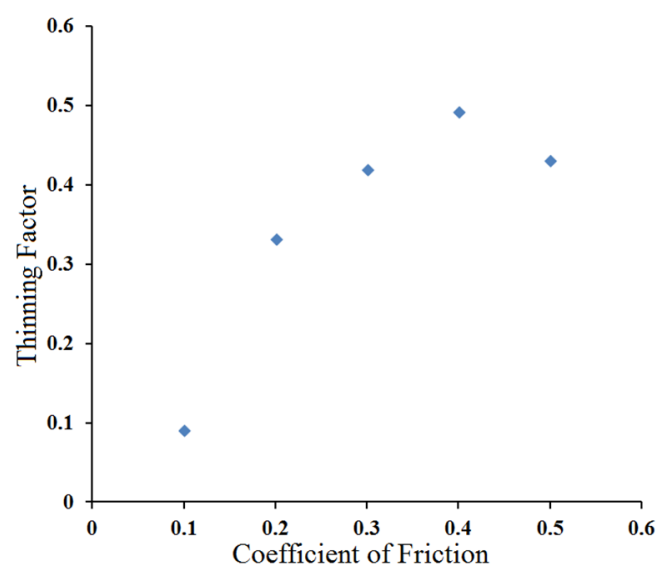

Figure 3. Thinning factor with different values of the coefficient of friction

Figure 4 shows the FEM estimated thickness profile of the triangular fins of a plate-fin heat exchanger formed with the optimal coefficient of friction of $\mathrm{fr}=0.40$. Notice that common PFHEs fin thicknesses range from 0.05 to 0.25 mm (Shah \& Sekulic, 2003).

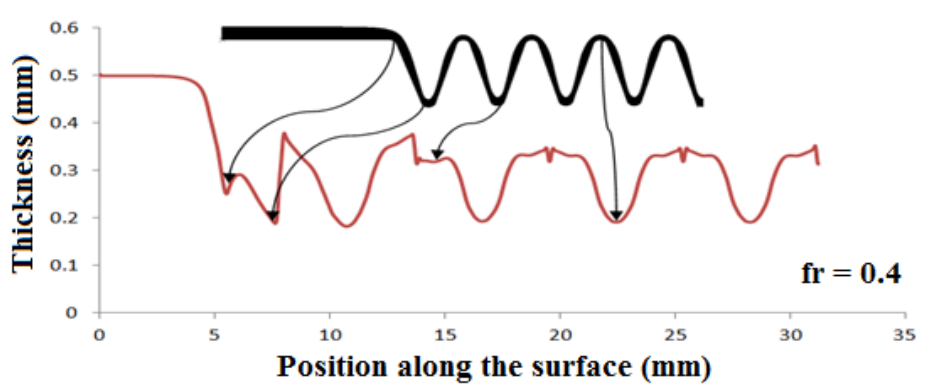

Figure 4. Predicted thickness profile of the formed sheet using a coefficient of friction of 0.4

Figure 5 shows the sequence of the simulation process for the SPF of plain triangular fins; the forming of the sheet became noticeable after $1000 \mathrm{sec}$. At $2500 \mathrm{sec}$ nearly half of the shape was formed, whereas the total forming time required was 2 hours $(7315 \mathrm{sec})$. The forming time is affected by many factors such as the die geometry, coefficient of friction, and the target strain rate.

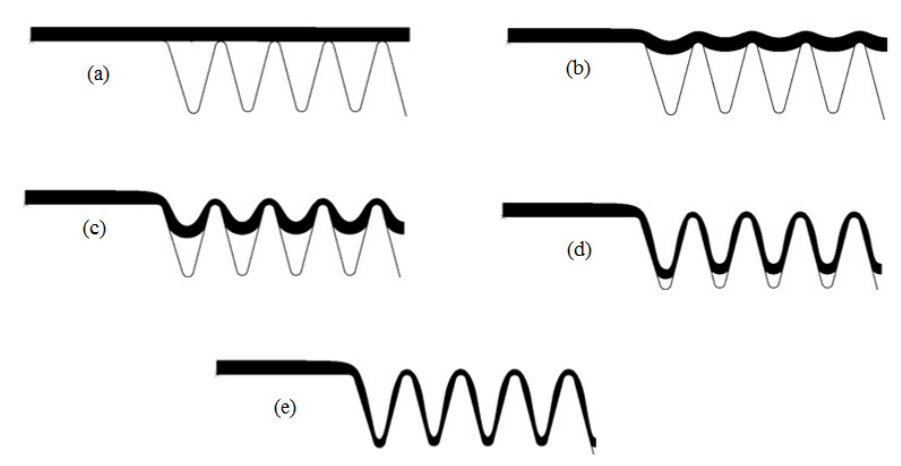

Figure 5. Simulation process of the SPF of plain triangular fins at forming times of (a) 0 (b) 1000 (c) 2500 (d) 5000 (e) 7315 seconds 


\subsection{Fins with Triangular Cross Sections Based on Aspect Ratio Optimization for SPF}

The aspect ratio is defined as the ratio of the width to the depth of the triangular channel. This ratio, W/D, indicates whether the channel is shallow or deep. The W/D ratio is an important factor in manufacturing and affects the pressure profile and thickness distribution. Figures 6-8 show the effect of the coefficient of friction and aspect ratio on the estimated thickness profiles. Figure 6 illustrates the thickness distributions of different aspect ratios for a coefficient of friction of $\mathrm{fr}=0.15$. It is noted that for a coefficient of friction of 0.15 , the SPF of the deep channels that have aspect ratios equal or lower than 0.9 are not recommended due to estimated excessive thinning of the sheet.

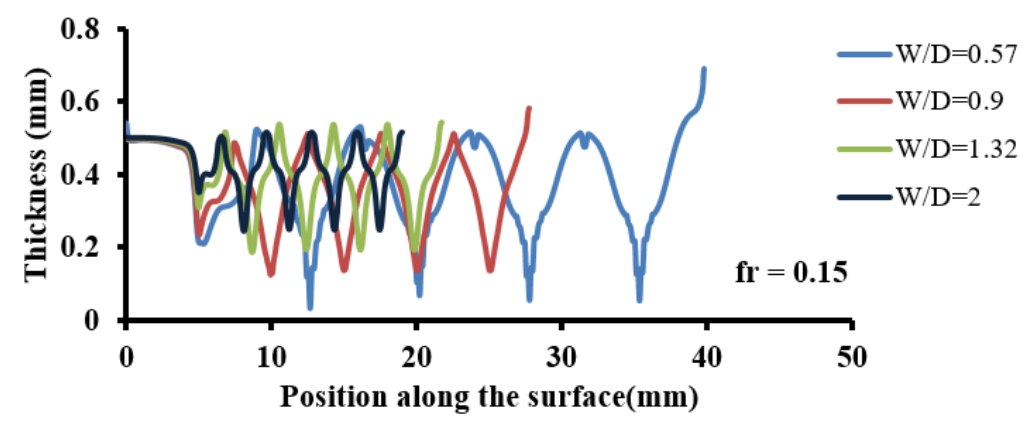

Figure 6. Thickness distribution for different aspect ratios with $\mathrm{fr}=0.15$

Figure 7 shows the thickness distributions of different aspect ratios for a coefficient of friction $\mathrm{fr}=0.35$. The figure demonstrates that the geometry that has an aspect ratio of 0.9 became potentially acceptable for SPF. Therefore, it can be seen that the severe thinning problem facing the forming of deep channels can be improved by increasing the coefficient of friction. However, even with further increasing the coefficient of friction to 0.5 as shown in Figure 8 , it is observed that the geometry that has an aspect ratio of 0.76 is not recommended for SPF.

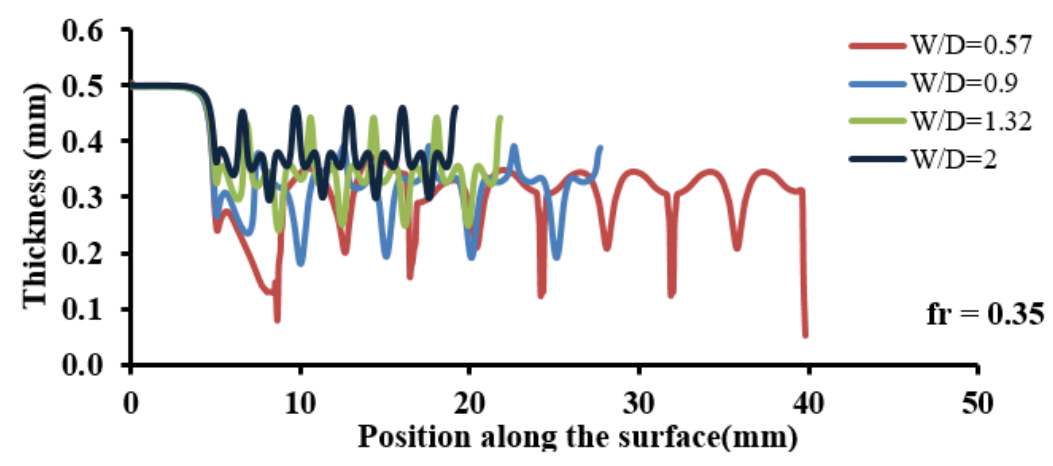

Figure 7. Thickness distribution for different aspect ratios with $\mathrm{fr}=0.35$

Based on an assumed coefficient of friction of 0.5 , the thickness distributions for different aspect ratios are shown in Figure 8. It is clear that increasing the W/D ratio causes an increase in the thickness. Which mean that shallow channels have better thickness distribution than deep channels. For W/D $<1$ (deep channels) the forming times are longer and thus more thinning would be expected. This result is consistent with the one obtained by Chandra et al. (Chandra \& Chandy, 1991). 


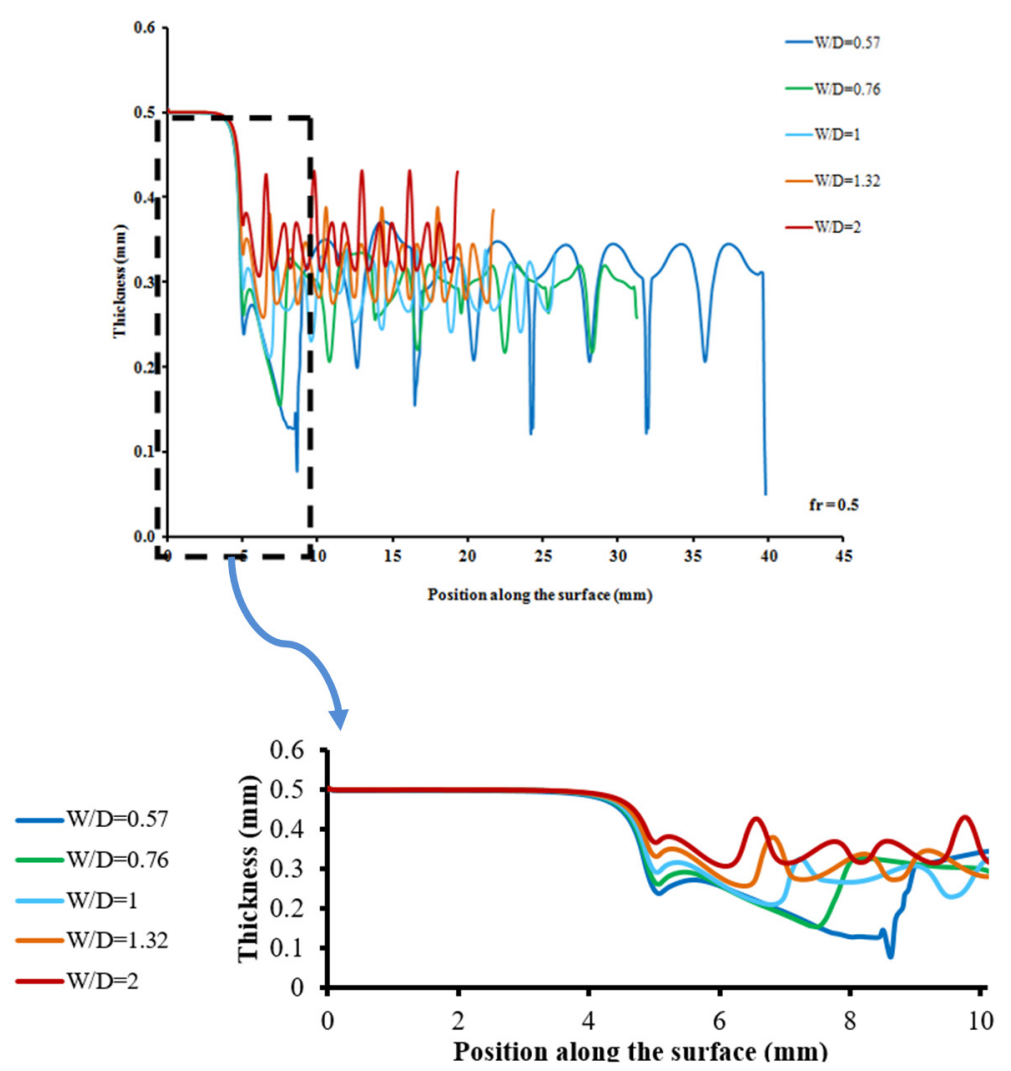

Figure 8. Thickness distributions for different aspect ratios with $\mathrm{fr}=0.5$

Figure 9 shows the pressure profile for different values of aspect ratios. The pressure cycle consists of three parts; a slow rise, a uniform part and a fast rise. For deep channels part 2 is the dominant one. On the other hand, for shallow channels part 2 disappears. This is because, in the later, bottom contact occurs almost immediately after the wrapping of the sheet around the entry radius.

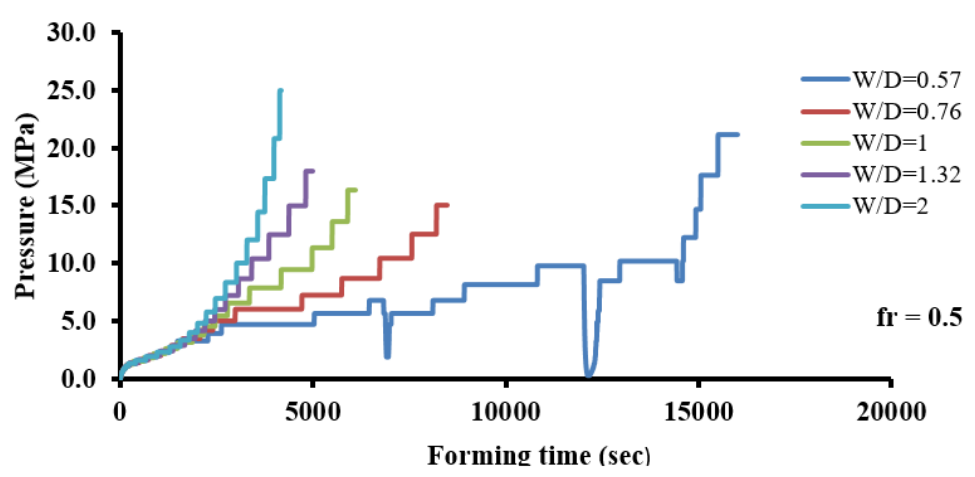

Figure 9. Pressure profile for different aspect ratios with $\mathrm{fr}=0.5$

\section{Conclusions}

In this paper, a design procedure that combines pressure drop analysis results with the manufacturing requirements for the SPF of fins with triangular channels was investigated. The SPF of an AA5083 plain fin with triangular cross-sections was simulated using ABAQUS ${ }^{\mathrm{TM}}$. A plane strain finite element model was used to predict the thickness distribution and forming times required for forming of triangular fins. Results reveal that, the less deep the triangular channels are, the better their quality becomes. It was also noticed that the thinning in the deep channels can be improved by increasing the coefficient of friction up to a certain limit. In addition, increasing the 
coefficient of friction reduces the required applied pressure on the sheet and causes the forming time to elongate. The present effort represents a necessary step toward designing complex fin geometry that offers a high heat load, uniform thickness distribution, and a low forming time.

\section{References}

Adderley, C. I., \& Hallgren, L. H. (1994). The design and manufacture of diffusion bonded plate-fin heat exchangers. Institution of Chemical Engineers; Taylor and Francis Issue, 106, 49-54.

Albakri, M. I., Jarrar, F. S., \& Khraisheh M. K. (2011). Effects of interfacial friction distribution on the superplastic forming of AA5083. J Eng Mater Technol, 133(3), 031008-031014. http://dx.doi.org/10.1115/ 1.4004159

Chandra, N., \& Chandy, K. (1991). Superplastic process modeling of plane strain components with complex shapes. J Mater Shap Technol, 9, 27-37. http://dx.doi.org/10.1007/BF02833630

Ghosh, A. K., \& Hamilton, C. H. (1980). Superplastic forming of a long rectangular box section-analysis and experiment. In: Proceedings of the 1980 American Society for Metals, Process Modeling Sessions, Materials and Process (pp. 303-331).

Harrison, N. R., Luckey, S. G., Friedman, P. A., \& Xia, Z. C. (2004). Influence of friction and die geometry on simulation of superplastic forming of Al-Mg alloys. In Advances in superplasticity and superplastic forming: Proceedings of the 2004 TMS Annual Meeting (pp. 301-309). Charlotte, North Carolina.

Jarrar, F. S., Abu-Farha, F. K., Hector Jr, L. G., \& Khraisheh, M. K. (2009). Simulation of high temperature AA5083 bulge forming with hardening/softening material model. $J$ Mater Eng Perform, 18(7), 863-870. http://dx.doi.org/10.1007/s11665-008-9322-5

Jarrar, F. S., Hector Jr, L. G., Khraisheh, M. K., \& Bower, A. F. (2010). New approach to gas pressure profile prediction for high temperature AA5083 sheet forming. J Mater Process Technol, 210(6), 825-834. http://dx.doi.org/10.1016/j.jmatprotec.2010.01.002

Jarrar, F. S., Hector Jr, L. G., Khraisheh, M. K., \& Deshpande, K. (2012). Gas pressure profile prediction from variable strain rate deformation paths in AA5083 bulge forming. J Mater Eng Perform, 21(11), 2263-2273. http://dx.doi.org/10.1007/s11665-012-0196-1

Jarrar, F., Liewald, M., Schmid, P., \& Fortanier, A. (2014). Superplastic forming of triangular channels with sharp radii. J Mater Eng Perform, 23(4), 1313-1320. http://dx.doi.org/10.1007/s11665-014-0878-y

Jarrar, F. S., \& Nazzal, M. A. (2013). Inclination angle effect on the thickness distribution in a superplastic formed long rectangular pan. Mater Sci Forum, 735, 155-161. http://dx.doi.org/10.4028/www.scientific.net/MSF. 735.155

Kays, W. M, \& London, A. L. (1964). Compact Heat Exchangers. McGraw-Hill, New York.

Lee, F. G., \& Hanna, M. D. (2005). Superplastic forming formula for aluminum channel panels. In: Proceedings of the 2005 ASME International Mechanical Engineering Congress and Exposition (pp 229-235). Orlando, FL, USA. http://dx.doi.org/10.1115/imece2005-79008

Luckey, Jr. G., Friedman, P., \& Weinmann, K. (2009). Design and experimental validation of a two-stage superplastic forming die. J Mater Process Technol, 209, 2152-2160. http://dx.doi.org/10.1016/j.jmatprotec. 2008.05.019

Qi, L., Gilles, F., Xigang, Y., Pierre, N., \& Lingai, L. (2011). Compact heat exchangers: a review and future applications for a new generation of high temperature solar receivers. Renewable and Sustainable Energy Reviews, 15, 4855-4875. http://dx.doi.org/10.1016/j.rser.2011.07.066

Shah, R. K., \& Sekulic, D. P. (2003). Fundamentals of Heat Exchanger Design. John Wiley \& Sons, Inc. http://dx.doi.org/10.1002/9780470172605

\section{Copyrights}

Copyright for this article is retained by the author(s), with first publication rights granted to the journal.

This is an open-access article distributed under the terms and conditions of the Creative Commons Attribution license (http://creativecommons.org/licenses/by/3.0/). 